\title{
Progress of Nanotechnology in Diabetic Retinopathy Treatment
}

This article was published in the following Dove Press journal:

International Journal of Nanomedicine

\author{
Yuxin Liu' \\ $\mathrm{Na} \mathrm{Wu}^{2,3}$ \\ 'Student Affairs Department, Shengjing \\ Hospital of China Medical University, \\ Shenyang, I 10004, People's Republic of \\ China; ${ }^{2}$ Department of Endocrinology, \\ Shengjing Hospital of China Medical \\ University, Shenyang, I I0004, People's \\ Republic of China; ${ }^{3}$ Clinical Skills Practice \\ Teaching Center, Shengjing Hospital of \\ China Medical University, Shenyang. \\ I 10004, People's Republic of China
}

\begin{abstract}
Diabetic retinopathy (DR) is a chronic diabetes complication that progressively manifests itself as blurred vision, eye floaters, distorted vision, and even partial or total loss of vision as a result of retinal detachment in severe cases. Clinically, patients who have undergone variations in the microcirculation of the ocular fundus are treated with laser photocoagulation to improve the circulation of retina; but for patients with macular edema, anti-vascular endothelial growth factor (anti-VEGF) drugs are generally injected to eliminate macular edema and improve vision. The worst cases are patients with fundus hemorrhage or proliferative vitreoretinopathy, for whom vitrectomy has been performed. At present, these clinical treatment methods have widely been used, providing satisfactory results. However, considering the low bioavailability and potential side effects of drugs and the inevitable risks in major surgery, DR prevention, and treatment as well as nerve tissue regeneration in the later stage have always been the focus of research. In recent years, nanotechnology has been increasingly applied in the medical field, leading to new ideas for DR treatment. This study aims to systematically review the research progress of nanotechnology in DR treatment.
\end{abstract}

Keywords: diabetes mellitus, diabetic retinopathy, nanotechnology, drug delivery

\section{Introduction}

\section{Nanotechnology}

Nanotechnology is a technology to study the properties and applications of materials in the range of $0.1 \mathrm{~nm}$ to $100 \mathrm{~nm}$. When the material reaches the nanometer size, the properties of the material will change and appear special properties. This material is composed of atoms, molecules and macroscopic materials. The difference between nanoparticles and bulk materials is mainly due to the relative increase of their surface area, that is, the surface of ultrafine particles is covered with ladder structure, which represents restless atoms with high surface energy. These atoms are easily bonded to foreign atoms and provide large surface active atoms due to particle size reduction. Nanotechnology, as a rapidly developing new discipline, is widely used in electronics, biomaterials energy, environmental science, chemistry, medicine and other aspects. Its application in medical field is mainly through the use of the special properties of nanoparticles to modify the surface of nanoparticles to form targeted, controllable release, easy to detect drug transport carriers, to provide a new method for the treatment of local lesions of the body, to open up a new direction for drug development, not only the special properties of nanoparticles also make it have an important application in disease prediction and monitoring. The application of nanotechnology in medicine has brought new prospects for
Correspondence: $\mathrm{Na} \mathrm{Wu}$

Shengjing Hospital of China Medical University, Shenyang, I I0004, People's Republic of China

Email 344I535223@qq.com
International Journal of Nanomedicine 2021:16 139|-|403

| 39 | 
the diagnosis and treatment of various diseases, and diabetes patients have also benefitted.

\section{Diabetes and Complications}

Diabetes mellitus is a group of metabolic diseases characterized by chronic hyperglycemia caused by multiple causes. It is a chronic disease that seriously threatens human health. The prevalence and incidence of diabetes in the world are rising sharply. According to the International Diabetes Alliance, the number of diabetes patients in the world reached 400 million in 2015 and 5 million in diabetes deaths. The total number of diabetes is expected to reach 600 million by 2040. Long-term hyperglycemia can damage all tissues and organs of the body, causing a series of complications. Acute complications include diabetic ketoacidosis, diabetic hyperosmotic coma, fungal vaginitis and many other infectious diseases. Chronic complications include diabetic foot, diabetic retinopathy, diabetic nephropathy and diabetic neuropathy. These chronic complications are often irreversible and have a huge burden on the health and economy of patients. With the hard work and unremitting efforts of researchers and medical workers, many chronic complications can be clearly diagnosed early in the disease, thus avoiding the deterioration of complications and irreversible damage to the body.

\section{Diabetic Foot}

The foot ulcers, infections, and deep tissue destruction associated with distal lower extremity neurological abnormalities and varying degrees of peripheral vascular lesions are the leading causes of diabetic non-traumatic amputees. Lauri et al are dedicated to studying radiolabeled leukocyte imaging $^{1}$ using 99 mTc-hexamethylamidoxime. Positron emission tomography ${ }^{2}$ is used to perform early imaging of diabetic foot complications in diabetic patients to achieve early detection of lesions.

\section{Diabetic Neuropathy}

Diabetic neuropathy includes central nervous system complications such as cerebral aging ischemic stroke and peripheral neuropathy such as distal symmetric polyneuropathy, focal single neuropathy, asymmetric multiple focal neuropathy, and multiple nerve root lesions. Chan et al in the latest research to explore the peptidepeptide co-assembly design method for the detection of biomarkers $\mathrm{C}$ peptides of diabetic neuropathy, desire for the diagnosis and intervention of early diabetic neuropathy through indirect monitoring of $\mathrm{C}$ peptide concentrations in the blood, they used a new screening strategy: complementary peptides that can be co-assembled with $\mathrm{C}$ peptides can be screened by blue laser excitation based on the polypeptide sequence assembled with $\mathrm{C}$ peptides. The structure information and $\mathrm{C}$ peptide were studied by ATRFTIR spectroscopy and CD spectroscopy. The results showed that $\mathrm{C}$ peptide was most strongly bound to TrpD. The second is Lys-D and Lys-L and there is no fixed binding rate between $\mathrm{C}$ peptide and any current complementary peptide, they point out that co-assembly between C-peptides and current 9-mer peptides is not optimal, but their research strategies still have important guiding significance in the discovery of new and more suitable complementary peptides. And its research method is also suitable for screening complementary peptides of amyloid protein, a biomarker of Alzheimer's disease, for Alzheimer's disease effective treatment preparation research to provide help. ${ }^{3}$

\section{Diabetic Nephropathy}

Diabetic nephropathy is the main cause of end-stage renal failure and the main cause of death of diabetes. Satirapoj et al summarized and analyzed the potential application of renal tubulointerstitial markers in diabetic nephropathy: cystatin $\mathrm{C}$ is an independent predictor of CKD progression in type 2 diabetes mellitus (T2DM); ${ }^{4,5}$ elevated kidney injury molecule 1 (KIM-1) was negatively correlated with decreased glomerular filtration rate, independent of albumin excretion rate; neutrophil gelatinase-associated lipocalin (NGAL) in the case of diabetic nephropathy, elevated NGAL levels occur independently of decreased glomerular filtration rate, and reflects tubulointerstitial injury and inflammation, ${ }^{6,7}$ can also predict the progression of T2DM kidney disease. ${ }^{5,8}$ Angiotensinogen can be used as a potential urine biomarker for the diagnosis of diabetic nephropathy, an early biomarker of RAAS activation in diabetic nephropathy; T2DM the patient starts to have significant albuminuria, you can detect elevated levels of periostin, and causes associated renal fibrosis and inflammation, ${ }^{9,10}$ the proportion of urinary MCP-1 and urinary EGF/MCP-1 was independently associated with renal progression. ${ }^{11}$

\section{Diabetic Retinopathy}

Hyperglycemic state due to diabetes are involved in the occurrence of DR, leading to high blood sugar levels in retinal vessels, increasing in vascular permeability, 
accumulating fluid in and under the retina, and causing edema and necrosis of nerve cells. Hyperglycemia can damage the blood-retinal barrier, and the leakage of blood from the central retinal artery, ciliary vessels, and the deep retina, which triggers the ischemic changes in the surrounding retina. This ischemic state activates the body's compensatory mechanisms, thereby promoting the formation and proliferation of new vessels, resulting in retinal detachment and resultant vision loss under stretching, the role of nanotechnology in the pathogenesis of diabetic retinopathy has been represented (Figure 1). Patients with diabetes for more than 10 years suffering varying degrees of DR as a chronic complication, causing blindness in severe case scenarios. ${ }^{12}$ According to the international clinical grading standard, ${ }^{13}$ DR can be classified into two categories including six stages: 1) nonproliferative diabetic retinopathy (NPDR) that includes stage I: microangioma and small bleeding points, stage II: hard exudates, and stage III: cotton-like soft exudates; 2) proliferative diabetic retinopathy (PDR) that includes stage IV: neovascularization, vitreous hemorrhage, stage $\mathrm{V}$ : fibrovascular proliferation, vitreous organization, and stage VI: retinal detachment and resultant blindness caused by stretching. Currently, if laser therapy is performed in a timely and appropriate manner, it can completely avoid vitreous hemorrhage and retinal neovascularization, achieving satisfactory clinical effects. Existing drugs for DR effectively relieve macular edema in the retina, and in advanced proliferative retinal diseases, vitrectomy clears the refractive media and sucks out the debris to remove the stent on which fibrous tissues develop. The removal loosens the stretching and restores the normal anatomical relationship of the retina, thereby keeping the eyeball intact and establishing conditions for laser photocoagulation or condensation. Hence, vitrectomy is considered to be the most effective treatment method of advanced DR. However, clinical drug therapies have certain limitations like the low solubility of drugs, poor penetrability through the BRB to reach the retina, toxicity to the body, and easiness to be degraded by enzymes in the body that results in the decreased duration of drug efficacy. Nanotechnology, due to its continuous development, has been increasingly applied to the prevention and treatment of DR, addressing many problems in traditional treatments. Its main advantages include a small diameter, high penetrability through the BRB, good biocompatibility, and some nanoparticles possessing favorable physical properties that are conducive to treatment effect observation. Reduced drug degradation in the body to achieve sustained release that promises to provide a stent for nerve tissue regeneration. An increasing number of nanomaterials are being synthesized or discovered and applied in the clinical treatment of

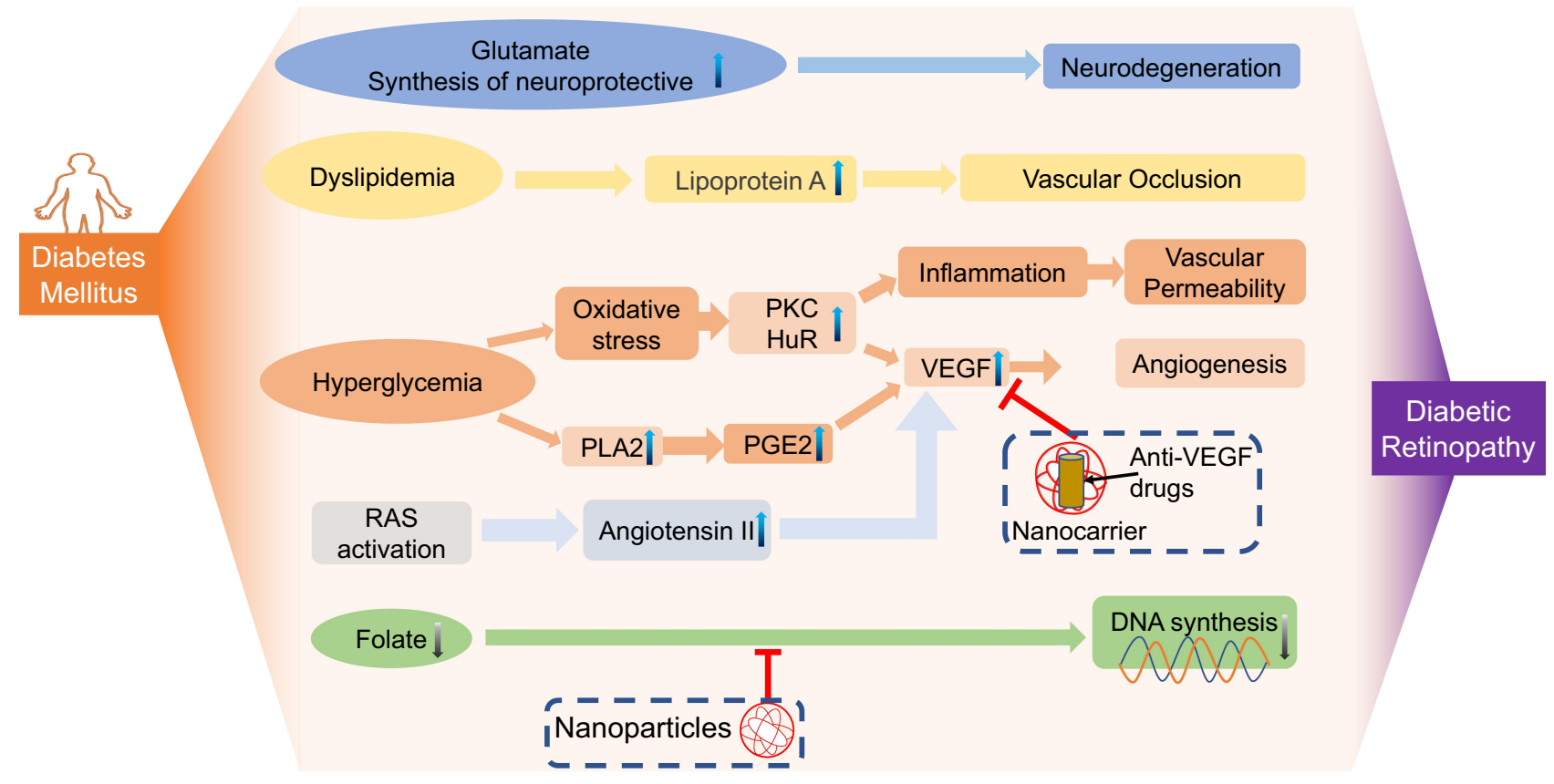

Figure I The role of nanotechnology in the pathogenesis of diabetic retinopathy.

Notes: Adapted from Pusparajah P, Lee LH, Abdul Kadir K. Molecular Markers of Diabetic Retinopathy: Potential Screening Tool of the Future? Front Physiol. 2016;7:200. Copyright @ 2016 Pusparajah, Lee and Abdul Kadir. Creative Commons Attribution License (CC BY). ${ }^{85}$ 
DR, contributing solutions to many problems. The application of nanotechnology in fundus examination also provides new advantages for DR prevention. However, the safety and feasibility of those new nanomaterials are still in the research stage, and investigating their application in DR treatment is of great importance. In view of these developments, this study aims to review the application and development of nanotechnology in DR treatment, exploring its contribution to the prevention and treatment of DR and its role in the regeneration of the nerve tissues damaged by DR.

\section{Traditional Therapies for DR}

Traditional therapies for DR comprising of laser therapy, vitrectomy, and conventional drugs to control hyperglycemia, hypertension, and hyperlipidemia are the points of consideration. These therapies have been widely applied to the clinical prevention and treatment of DR, delivering satisfactory efficacy and superiority in inhibiting retinal neovascularization, relieving retinal macular edema, and removing the stretching of fibrous tissues during the proliferation period for the retina. Although extensive clinical trials have proven their application value, these therapies are inevitably disturbed by certain limitations in clinical application.

\section{Laser Therapy}

Laser therapy is mainly used for proliferative retinopathy. The commonly used laser wavelengths are $532 \mathrm{~nm}$ and $577 \mathrm{~nm}$. Beams of light are focused on the site of retinal hemorrhage to raise the temperature for protein degeneration and liposome necrosis, thereby stopping the bleeding caused by microaneurysm rupture and preventing the formation of ocular hematomas. This therapy is still used in clinical practice. Jiang ${ }^{14}$ treated 45 patients with diabetes mellitus using panretinal photocoagulation (PRP) and evaluated the efficacy, concluding that PRP can promote neovascularization, improve macular edema and vision, and prevent the deterioration of the disease. However, laser treatment is often complicated with vitreous hemorrhage, as mentioned by $\mathrm{Bi}$ et $\mathrm{al}^{15}$ when reviewing the progress of photocoagulation application in DR treatment, in their research, the found that the choice of delayed photocoagulation leads to a serious loss of vision of $6.5 \%$, and timely PRP can reduce the risk of serious loss of vision to $3.8 \% \sim 4.7 \%$, significantly reduced. In the follow-up of 192 patients treated with retinal laser photocoagulation, Kleinmann et al have reported a high incidence of $39 \%$ vitreous hemorrhage. ${ }^{16}$ Besides, this therapy may destroy some retinal cells and often results in permanent scotomas in the visual field. ${ }^{17-20}$ PRP can worsen night vision and delay light-to-dark adaptation. ${ }^{21-23}$

Retinal laser photocoagulation mainly blocks the ischemic areas around the retina, reduces the stimulation of ischemia for vascular endothelial growth factors (VEGFs), and inhibits the diffusion of fibrovascular toward the surroundings, thereby lowering the possibility of intravitreal hemorrhage. However, it has a key limitation, as more than two surgeries are necessary to maintain a good retina. ${ }^{24}$

\section{Vitrectomy}

Vitrectomy is used in patients with advanced DR manifested as intravitreal hemorrhage and neovascularization, in an attempt to prevent vision loss and visual field defects. The mechanism of this therapy is to remove blood from the vitreous and prevent retinal detachment caused by internal injury, ${ }^{25}$ which is still widely used in clinical practice. Owing to the advances in minimally invasive techniques, it has upgraded from the initially traditional $20 \mathrm{G}$ vitrectomy to the $23 \mathrm{G}$ minimally invasive vitrectomy, which is characterized by smaller surgical incisions and higher incising efficiency. Brănişteanu et $\mathrm{al}^{26}$ performed $20 \mathrm{G}$ and $23 \mathrm{G}$ vitrectomies for two groups of patients with DR separately and followed up with them for at least 12 months. The results showed that vitrectomy was an effective therapy for DR and there was no significant difference in operational complexity and retinal repair between $20 \mathrm{G}$ and $23 \mathrm{G}$ vitrectomy. Besides, they compared the therapeutic effects of these two methods and concluded that $23 \mathrm{G}$ vitrectomy is likely to cause serious complications such as iatrogenic retinal break and the inherent postoperative ocular sequelae, such as cataract formation. ${ }^{27,28}$ Therefore, the safety of a vitrectomy has become the main problem that limits its clinical application. Naruse, Veritti et al ${ }^{29,30}$ followed up 185 cases who received $25 \mathrm{G}$ or $27 \mathrm{G}$ minimally invasive vitrectomy (included 64 undergoing 25G vitrectomy and 125 undergoing $27 \mathrm{G}$ vitrectomy) and compared the two minimally invasive vitrectomy systems. They concluded that both $25 \mathrm{G}$ and $27 \mathrm{G}$ vitrectomy systems were safe and effective for PDR treatment and promised the early recovery of vision after the operation. Nathan et al concluded from a controlled trial: In Type I diabetes, early vitrectomy resulted in visual acuity of $10 / 20$ or better in $36 \%$ of eyes whereas deferral of vitrectomy resulted in $10 / 20$ or better visual acuity in $12 \%$ of eyes. There was no 
advantage of early vitrectomy found in Type 2 diabetes patients. $^{31}$

\section{Drug Therapy}

Drug therapies are designed to reduce the expression of VEGF by lowering vascular permeability and abating the damage to the BRB. The methods of drug administration mainly include periocular administration, subretinal administration, and intravitreal injection.

\section{Drugs for Microcirculation Disorders}

Pancreatic kininogenase degrades kininogen in the body into kinin, which relaxes capillaries to increase capillary blood flow, activates the activity of the fibrinolytic system, and dissolves the microthrombus formed under a hypercoagulable state, thereby improving retinal blood flow, correcting hypoxia, reducing protein exudation, and eliminating hemangioma. According to the clinical research by Lin et al compound xueshuantong capsule combined with pancreatic kininogenase can effectively improve microcirculation, increase blood flow, anticoagulation, thrombolysis, and decrease blood viscosity, showing satisfactory efficacy for NPDR. ${ }^{32}$

\section{Drugs for Vascular Endothelium Protection}

Calcium dobesilate $(\mathrm{CaD})$ inhibits oxidative stress and inflammation, reduces BRB injury, and improves vascular permeability and vascular leakage. It promises to relieve DR-induced fundus diseases, improve vision, inhibit neovascularization, and delay the progress of $\mathrm{DR}$. $\mathrm{CaD}$ can also be used as adjuvant therapy for photocoagulation. ${ }^{33}$

\section{Anti-VEGF Drugs}

Anti-VEGF type of drug reduces the formation of retinal neovascularization mainly by inhibiting VEGF. Intravitreal injection is generally used to elevate drug concentration in the eye and prevent the formation of proliferative tissues, hence improving the efficacy of retinal detachment surgery. The anti-VEGF drugs commonly used in DR treatment include ranibizumab, bevacizumab, and infliximab. For moderate to severe DR, infliximab shows better visual recovery efficacy. ${ }^{34}$

\section{Other Anti-Angiogenesis Drugs}

Squalamine ${ }^{35}$ promotes visual recovery by inhibiting vascular growth factors such as PDGF and b-FGF. Moreover, it is found that AKB-9778 activates Tie2 by blocking vascular endothelial protein tyrosine phosphatase (VEPTP), a negative regulator of Tie2, thereby reducing vascular permeability and DR incidence. ${ }^{36}$

\section{Steroid Hormones}

Triamcinolone acetonide, discovered in 1970, is currently the most effective steroid drug used for PDR. ${ }^{37}$ The other two alternatives are dexamethasone sodium phosphate ${ }^{38}$ that reduce the damage to the BRB by exerting its antiinflammatory effects, and fluocinolone acetate that is injected into the vitreous to relieve bruising. However, the improvement of the bioavailability and the targeting of these drugs to the retina are critical challenges to be addressed.

\section{Application Progress of Nanotechnology in DR Prevention}

Regarding DR prevention, besides controlling blood pressure and sugar levels and avoiding strenuous exercise, regular fundus examination is necessary to identify DR earlier. Fluorescein angiography that emerged in the 1960s is considered as the gold standard for DR fundus examination. In the procedure, sodium fluorescein is adopted as the fluorescent dye that is quickly injected into the antebrachial vein. When the agent flows into retinal vessels with blood, angiograms are obtained by photographing the fluorescent green light emitted from the dye while the blood vessels return to the eye. With the angiograms obtained, the process of the dynamic cycling of blood within the retina can be observed, thus revealing the microstructure and microcirculation changes of fundus vessels. Qian et al explored the application of polyethyleneimine which modified fluorescein sodium (PEI-NHAc-FS) nanoparticles (NPs) in fundus fluorescein angiography as well as its safety. ${ }^{39}$ The research indicated that PEI-NHAc-FS NPs can effectively reduce the retention of fluorescein sodium in the body and develop retinal blood vessels, so it can be used to examine the fundus and identify the onset of DR. Moreover, PEI-NHAc-FS NPs are characterized by simple preparation methods, good biocompatibility, stable properties, and a high metabolic rate. However, similar to other fundus angiography techniques, it inevitably causes invasiveness to patients. Vadanasundari Vedarethinam assumed that vanadium core-shell nanorods can be used to detect metabolic changes in DR, and to monitor the severity and make possible early detection and diagnosis of DR. Inspired by this concept, Vadanasundari et al used vanadium oxide loaded on silica nanorods and 
constructed a variety of vanadium core-shells that consisted of different elements and structural parameters in an attempt to assist laser desorption ionization mass spectrometry and draw plasma metabolic fingerprints of diabetic retinopathy. In the future, it is necessary to perform blood testing for patients with diabetics to identify DR earlier, which is of great benefits to the prevention and treatment of DR. Besides, the method developed by Vadanasundari et al can be used to distinguish the severity degrees of non-proliferative diabetic retinopathy, delivering noticeable performance in disease grading. Therefore, it provides a new reliable and efficient blood testing strategy for DR. ${ }^{40}$ This latest research result has been applied in clinical trials.

In addition to monitoring and auxiliary examinations, hypoxia is another factor that needs attention to prevent DR. It is the precursor stage of retinal neovascularization, so identifying hypoxic areas in retinal tissue and treating hypoxia earlier promise to delay the onset of DR. Studies have shown that Hypoxia-inducible factor-1 (HIF-1) can reduce the expression of IL- 6 and TNF-a in DR ${ }^{41}$ and the expression of miR-125b-5p and miR-146a-5p in the retina, ${ }^{42}$ and upregulate the expression of growth factors such as VEGF and PDGF. HIF-1 antagonists targeted to hypoxic tissues are considered to be a great way to prevent DR. Daunorubicin and doxorubicin (DXR) inhibit the transcriptional activity of HIF1 by blocking its binding to DNA, but they have poor water solubility, precipitating on the surface of the retina after intraocular injection. Iwase et al used polysebacic acid (PSA)polyethylene glycol (PEG) nanoparticles to continuously deliver daunorubicin to the retina and observed that after intraocular injection of a diabetic rabbit model, the antagonist was slowly released in a controlled manner for more than 105 days. Additionally, PSA-PEG nanoparticles continuously inhibit neovascularization in the retina for more than 35 days. The sustained-release of PSA-PEG is conducive to the prevention of DR, and it is non-toxic to the retina. ${ }^{43}$ However, no conclusion has yet been reached as to whether PSA-PEG nanoparticles can safely play a role in the human retina as it is used in the experimental animal retina, and more clinical trials are necessary to warrant this problem.

\section{Progress of Nanotechnology in DR Drug Treatment}

Nanotechnology application to DR treatment has unique advantages. Currently, most of the nanomolecules used as drug carriers have a diameter ranging from 1 to 100 nanometers, which allows the drugs to easily pass through the BRB barrier. Most importantly, the property of nanomolecules combining with specific receptors on retinal pigment epithelial cells allows them to reach the epithelial cells in a targeted manner, thereby achieving the goal of DR treatment. The high blood glucose levels in the retinal vessels that trigger DR have two main sources. Badr et al experimentally proved that glucose transporter 1 (GLUT1) has reduced expression in isolated retinal capillaries and the neural retina. Accordingly, the high blood glucose levels in the DR retina may be attributed to increase glucose entering into the retina through the retinal pigment epithelium (RPE)-choroid interface. ${ }^{44}$ In subsequent studies, Ulas et al noted Streptozotocin-induced diabetes of a 2-week or 2-month duration reduced GLUT1 expression in the retina and its microvasculature by approximately $50 \%$, but it resulted in no reduction in GLUT1 expression in cerebrum or its microvessels. The density of capillaries in retinas of diabetic animals did not change from normal, and so the observed decrease in GLUT1 expression in the retina and retinal capillaries of diabetic animals cannot be attributed to fewer vessels, they concluded that the elevated expression levels of GLUT1 and GLUT3 in the diabetic retina, which is responsible for the accumulation of glucose in the retina, thereby creating a high glucose microenvironment that induces the occurrence of DR. ${ }^{45}$ Based on the above findings, Gao et al at Jilin University prepared hyaluronic acid nanocarriers that can target the CD44 receptor of RPE cells. Also, mouse diabetic models were established and performed controlled experiments that included a control group and a diabetic group; GLUT1 coated by hyaluronic acid nanocarriers was injected in the subretinal space of the diabetic group. Their experimental results showed that hyaluronic acid nano-particles used as a DR drug carrier can significantly control the blood sugar level in the retina of diabetic mice, ${ }^{46}$ which further verified the inferences made by Ulas and Badr et al. In the experiment, they collected and observed the optic nerve specimens of rats, confirming that NPs also have a neuroprotective effect. According to the observation results of the thickness of the retina's outer nuclear layer, GENPs is safe and non-toxic to the retina. Hao et al prepared an amphiphilic nanosystem composed of hydrophobic polycaprolactone (PCL) and hydrophilic pluronic F68 (PF68) that was used to load hyaluronic acid (HA), a steroidal drug effective in the treatment of DR. In the experiment, HA was used as eye drops for diabetic rats. Controlled experiments suggested that PCL-PF68 NPs show optimal encapsulation efficiency for tannic 
acid (TA), a hydrophobic drug, and perform noticeably well in controlling the release of HA, allowing it to exist in the retina for a longer time. The measurement results of retinal thickness also verified the safety of PCL-PF68NPs in DR treatment. After 24h exposure at the test concentration, the cell survival rates of NPBs and NPDs are both $100 \%$, suggesting that NPBs and NPDs have good cell compatibility. This quality can well avoid the strong side effects of drugs when they are applied to DR treatment, remarkably reducing the probability of adverse reactions. Therefore, this nanosystem serves as a non-invasive and safe carrier of drugs to eye tissue, ${ }^{47}$ but when used as a lipid carrier, it has problems such as low drug loading capacity and poor stability during storage. In recent studies, an increasing number of new nanomaterials that can be used for DR treatment have been developed, kinds of nanomaterials in DR treatment (Table 1) have been investigated.

\section{Application of Nanotechnology in DR Drug Delivery and Monitoring}

In a research article published in 2016, Amadio et al treated

DR using SLN, liposomes, and a nanosystem that contains siRNA to silence HuR expression. Through STZ induction, they established a diabetic rat model, which HuR-silencing siRNA encapsulated by SLN and liposomes was injected. After measuring the expression of HuR and VEGF genes in the retina of the experimental and control groups and observing the histology of the retina, they verified the inhibitory effect of HuR-silencing siRNA on the expression of mRNA encoding VEGF gene. Also, they confirmed that nanocarriers can carry miRNA through the BRB smoothly, thereby achieving the targeted treatment of $\mathrm{PR} .{ }^{58}$ This cationic lipidbased non-viral carrier promises to be widely used for DR drug delivery due to its advantages of freedom from immune responses of the body, simple production, and affordable price. Based on the "host-guest" interaction between MPEG and $\alpha-\mathrm{CD}$, Zamani et al managed to release Dex and Avastin separately from the supramolecular hydrogel as a nanocarrier that is composed of methoxy polyethylene glycol/polycaprolactone (mPEG-PCL) micelles and $\alpha$ cyclodextrin $(\alpha-C D)$, in an attempt to treat inflammatory corneal neovascularization in a rat model. ${ }^{59}$ The results showed that $70 \%$ of Avastin was released within 5 days and $70 \%$ of Dex was released within 1 day, suggesting that DEX/Avastin play a role in inhibiting retinal neovascularization and that PEG-PCL hydrogel as a drug carrier is effective in achieving sustained drug release. Italian scientists Amato et al developed another possible effective method for DR treatment in 2020, that is, combining the somatostatin analog octreotide (OCT) that displays important neuroprotective and anti-angiogenic properties with magnetic nanoparticles (MNPs), and injecting the combination into the eyes of the rats. ${ }^{60}$ Results indicated that the significant effect of MNP-OCT is maintained at lower doses (100-fold in HRECs and 10-fold in retinal explants) compared to free OCT, demonstrating a strong improvement of the drug bioactivity following binding to MNPs. Besides, MNPs produced no toxicity in the rats and showed good compatibility, prolonging the release of OCT in the rat retina for several months while not affecting its efficacy. Therefore, MNPs greatly reduce the frequency of injection of anti-VEGF antibodies, making it easier to sustain an effective drug concentration.

The superiority of nanotechnology in DR treatment is not only reflected in its nano-scale that contributes to drugs smoothly passing through the BRB but also in some properties unique to nanoparticles, which provide convenience for therapeutic drug monitoring. In 2019, Shoval et al ${ }^{61}$ coated the two anti-VEGF drugs, bevacizumab and aflibercept, with carbon nanodots (C-dots) and separately injected the combinations into diabetic rats. By taking advantage of the inherent fluorescence of C-dots, they performed non-invasive monitoring of intraocular drug concentration, thereby avoiding the damage to the eyes caused by invasive monitoring. The research results showed that C-dots used as the outer envelope of bevacizumab and aflibercept can effectively prevent the degradation of the drugs before they reach the retina, thereby increasing the effective drug concentration in the retina of the eye and more efficiently inhibiting VEGF-induced neovascularization in choroidal blood vessels. Hence, the development from NPDR to PDR can be prevented, and the retinal tissue effectively protected.

\section{Application of Nanotechnology in Retinal Regeneration}

\section{Nanoscaffolds for Retinal Regeneration}

PDR causes damages to the retina that contains seven major cell types (RPE, cone cells, rod cells, horizontal cells, bipolar cells, retinal ganglion cells, and amacrine cells). Among them, RPE is the main nutritional source of the retina, so the research focuses on retinal regeneration. At present, there are two main types of nanomaterials 
Table I Nanomaterials in DR Treatment

\begin{tabular}{|c|c|c|c|c|c|c|c|}
\hline Nanomaterials & Time & Diameter & Source & $\begin{array}{l}\text { Loaded } \\
\text { Drug }\end{array}$ & Efficacy & Existing Problems & Reference \\
\hline CNE & 2014 & N/A & $\mathrm{N} / \mathrm{A}$ & $\begin{array}{l}\text { Hydrophilic/ } \\
\text { protein-based } \\
\text { drugs }\end{array}$ & $\begin{array}{l}\text { The retention time of drugs in the } \\
\text { eyeball was prolonged and the } \\
\text { adhesion of the mucus to the } \\
\text { retina was enhanced through the } \\
\text { electrostatic interaction with the } \\
\text { human eye mucosa. }\end{array}$ & & $\begin{array}{l}{[50]} \\
{[48]}\end{array}$ \\
\hline $\begin{array}{l}\text { SLN } \\
\text { NLC }\end{array}$ & 2013 & $288 \mathrm{~nm}$ & $\begin{array}{l}\text { Stearic acid, } \\
\text { castor oil }\end{array}$ & $\begin{array}{l}\text { Triamcinolone } \\
\text { acetonide }\end{array}$ & $\begin{array}{l}\text { Due to the good biocompatibility } \\
\text { of physiological lipids, PEG loading } \\
\text { further improves drug } \\
\text { bioavailability in the eye and } \\
\text { reduces drug irritation to the } \\
\text { ocular mucosa and the } \\
\text { occurrence of intraocular } \\
\text { rejection. }\end{array}$ & $\begin{array}{l}\text { The drug loading capacity is low, } \\
\text { and the stability is poor during } \\
\text { storage, which may lead to } \\
\text { particle size growth and drug } \\
\text { degradation. }\end{array}$ & $\begin{array}{l}{[41]} \\
{[50]-[55]}\end{array}$ \\
\hline $\begin{array}{l}\mathrm{SiO} 2-\mathrm{CeCl} 3 \\
\text { nanoparticles }\end{array}$ & 2014 & $130 \mathrm{~nm}$ & $\mathrm{~N} / \mathrm{A}$ & $N / A$ & $\begin{array}{l}\text { Low-concentration silica-cerium } \\
\text { (III) chloride }(\mathrm{CeCl} 3) \text { and } \alpha \text { - } \\
\text { crystal protein quickly form a } \\
\text { preliminarily stable conjugate, } \\
\text { inhibiting advanced glycation end } \\
\text { products (AGEs) and restraining } \\
\text { the production of intracellular } \\
\text { reactive oxygen species as well as } \\
\text { oxidative stress. }\end{array}$ & & {$[42]$} \\
\hline $\begin{array}{l}\text { Silica } \\
\text { nanoparticles }\end{array}$ & 2012 & $N / A$ & $\mathrm{~N} / \mathrm{A}$ & $N / A$ & $\begin{array}{l}\text { Oxygen-induced abnormal retinal } \\
\text { neovascularization is effectively } \\
\text { reduced, and VEGF receptor-2 is } \\
\text { induced to phosphorylate by } \\
\text { restraining VEGF in vitro, thereby } \\
\text { blocking the activation of ERKI/2 } \\
\text { and inhibiting angiogenesis } \\
\text { induced by VEGF in vitro. }\end{array}$ & & [43] \\
\hline AgNPS & 2019 & $35 \mathrm{~nm}$ & $\begin{array}{l}\text { Mulberry } \\
\text { leaf extract }\end{array}$ & $\mathrm{N} / \mathrm{A}$ & $\begin{array}{l}\text { AgNPS prepared by mulberry leaf } \\
\text { extract using an environmentally } \\
\text { friendly method have a } \\
\text { satisfactory treatment effect on } \\
\text { PR. }\end{array}$ & $\begin{array}{l}\text { There is genotoxicity, which may } \\
\text { be attributed to the elevated } \\
\text { intracellular ROS induced by } \\
\text { AgNPS and the resultant DNA } \\
\text { damage. }\end{array}$ & $\begin{array}{l}{[44]} \\
{[56]} \\
{[58]}\end{array}$ \\
\hline GNP & 2011 & $50 \mathrm{~nm}$ & $\mathrm{~N} / \mathrm{A}$ & $N / A$ & $\begin{array}{l}\text { VEGFR-2 autophosphorylation } \\
\text { induced by VEGF is suppressed, } \\
\text { thereby inhibiting the activation of } \\
\text { ERKI/2. No retinal toxicity is } \\
\text { found, nor the viability of retinal } \\
\text { microvascular endothelial cells is } \\
\text { affected. }\end{array}$ & $\begin{array}{l}\text { Cytotoxicity may occur as the } \\
\text { particle size shrinks. A lot of } \\
\text { experiments are needed to } \\
\text { identify an appropriate particle } \\
\text { size. }\end{array}$ & $\begin{array}{l}{[39]} \\
{[45]}\end{array}$ \\
\hline MNP & 2020 & $50 \mathrm{~nm}$ & $\begin{array}{l}\text { Iron oxide, } \\
\text { ferric oxide }\end{array}$ & Octreotide & $\begin{array}{l}\text { MNP has no toxicity to human } \\
\text { retinal cells, and when combined } \\
\text { with octreotide, it does not affect } \\
\text { the anti-angiogenesis and anti- } \\
\text { apoptosis effects of octreotide; } \\
\text { MNP may be first located on the } \\
\text { RPE and then on the entire retina. }\end{array}$ & $\begin{array}{l}\text { Compared with other } \\
\text { nanoparticles, magnetic iron } \\
\text { oxide nanoparticles (MIONs) are } \\
\text { less biologically toxic, but further } \\
\text { studies are necessary to verify } \\
\text { their safety. }\end{array}$ & $\begin{array}{l}{[39]} \\
{[57]}\end{array}$ \\
\hline
\end{tabular}


Table I (Continued).

\begin{tabular}{|l|l|l|l|l|l|l|l|}
\hline Nanomaterials & Time & Diameter & Source & $\begin{array}{l}\text { Loaded } \\
\text { Drug }\end{array}$ & Efficacy & Existing Problems \\
\hline PLGA & 2012 & 2013 & $20-250 \mathrm{~nm}$ & $\begin{array}{l}\text { Lactic acid, } \\
\text { glycolic acid }\end{array}$ & $\begin{array}{l}\text { Bevacizumab } \\
\text { or other } \\
\text { protein/ } \\
\text { enzyme drugs }\end{array}$ & $\begin{array}{l}\text { PLGA is safe for the retina, widely } \\
\text { used for drug delivery. PLGA } \\
\text { nanoparticles can protect the } \\
\text { protein from inactivation and } \\
\text { aggregation in the presence of } \\
\text { albumin. }\end{array}$ & $\begin{array}{l}\text { The solubility in water is relatively } \\
\text { poor, and the nanoparticles } \\
\text { formed are large in size, so they } \\
\text { tend to be cleared by the liver } \\
\text { and spleen, reducing drug } \\
\text { concentration in the retinal } \\
\text { tissue. }\end{array}$ \\
\hline $\begin{array}{l}\text { Chitosan-based } \\
\text { nanoparticles }\end{array}$ & 2014 & N/A & N/A & N/A & $\begin{array}{l}\text { Chitosan-based nanoparticles } \\
\text { enable bevacizumab to be } \\
\text { sustainedly released in the retina, } \\
\text { thereby inhibiting retinal } \\
\text { neovascularization. }\end{array}$ & [49] \\
\hline
\end{tabular}

Abbreviations: DR, diabetic retinopathy; CNE, cationic nanoemulsion; SLN, solid lipid nanoparticles; NLC, nanostructured lipid carrier; AgNPS, silver nanoparticles; GNP, gold nanoparticles; MNP, magnetic nanoparticles; PLGA, polylactic acid-glycolic acid.

used for retinal regeneration: electrospun nanofibers and self-assembled nanofibers. The common natural polymers in electrospun nanofibers are fibrin, gelatin/chitosan, laminin, collagen, and hyaluronic acid, while the common synthetic polymers include poly(L-lactic-co- $\varepsilon$ caprolactone) (PLCL), PCL, poly (lactic-co-glycolic acid) (PLGA), and poly (L-lactic acid) (PLA). Under normal circumstances, there are chemical property differences between natural and synthetic polymers, which lead to natural polymers more suitable for cell attachment and biological activity. Therefore, natural nanopolymers show larger attraction for cells, but they are obscured by synthetic polymers in terms of mechanical strength and halflife. To be specific, synthetic polymers are easier to be designed and controlled in terms of biodegradation, mechanical strength, and transport properties, facilitating the acquisition of an extracellular analog matrix used for cell growth and differentiation. In 2016, Milton Wyman established a radiating nanofiber scaffold to mimic the oriented nerve fibers and found that $72 \%$ of the nerve axons grew along the scaffold. ${ }^{62}$ According to a research, ${ }^{63}$ nanofibers in a diameter of about $200 \mathrm{~nm}$ can mimic the distribution of nerve fibers more accurately than those in a diameter of about $1000 \mathrm{~nm}$, thereby promoting retinal regeneration. For some neurons, retinal nerve function is lost on the edge of death. Therefore, measures have to be taken to promote the regeneration of endangered neurons. In this end, a multichannel self-assembling peptide nanofiber scaffold that contains nerve growth factor (NGF) and brain-derived growth factor (BDGF) has been developed- the NGF is immediately released from the scaffold to assist the initial stage of nerve axon regeneration, and the BDGF is constantly released to promote axon growth and myelin sheath formation. ${ }^{64}$ Similarly, conductive polypyrrole and single-electron layer graphite nanoparticles were experimentally added into the scaffold, and the growth of retinal ganglion cells was found to have increased by up to $137 \%$ under electrical stimulation. ${ }^{65}$ Distribution of nerves in the body using nano-scaffolds contributes to the regeneration of retinal tissues, thereby preventing the complete necrosis of nerve tissues.

Jing et al created multidomain peptide nanofiber hydrogel with sequence K2(SL)6K2, which, after entering the host retinal tissue, triggers an inflammatory response and causes the host cell to infiltrate, followed by the release of a large number of growth factors and cytokines. These growth factors and cytokines are to be diffused into the hydrogel and initiate local vascularization after degradation, thus resulting in innervation. ${ }^{66}$ Soleimannejad et al studied the applicability of fibrin gel as a scaffold for differentiation of conjunctival mesenchymal stem cells into photoreceptor cells using scanning electron microscopy, rheology testing, biodegradation rate determination, and culture of conjunctival mesenchymal stem cells. The results of sem analysis showed that the pore structure of fibrin scaffold was good, conjunctival mesenchymal stem cells combined well in all gels, and there was good compatibility between cells and fibrin gel its physical properties can be easily adjusted to environmental ${ }^{67-69}$ appropriate for photoreceptor cell preparation. The 
rheological properties of fibrin gels were measured by rheometer and the biodegradation rate of fibrin was determined for two weeks. The results of these tests show that the elastic modulus and constant degradation of hydrogels contribute to cell growth and proliferation. Compared with the cells cultured on the surface of tissue culture plate, the activity of conjunctival mesenchymal cells cultured on fibrin gel was significantly enhanced and had no cytotoxicity. Good biocompatibility and biodegradability. ${ }^{70}$

\section{Nanomaterials as Gene Delivery Devices to Reprogram Cells for Retinal Regeneration}

In addition to these nanoscaffolds, nanomaterials also as gene delivery devices to reprogram cells for ocular regeneration, the first type of non-viral gene nanocarriers investigated for gene delivery for ocular tissue regeneration is liposome-protamineDNA (LPD) complexes, they better protected the plasmid DNA from enzymatic degradation and offered higher gene expression. ${ }^{71}$ Inclusion of cholesterol as a helper lipid could further increase the in vivo transfection efficiency of the LPD nanocarriers with less need of the cationic lipids. ${ }^{72}$ The second type of nanocarriers that have good gene delivery potential is mesoporous nanoparticles that contain pores with diameters between 2 and $50 \mathrm{~nm}$. The porous structure and high surface area of mesoporous nanoparticles enable high gene loading/ encapsulation and enhanced transfection, ${ }^{73,74}$ Cao et al found that, based on fluorescent microscopic results, plasmid DNA encoding VEGF-loaded mesoporous iron oxide nanoparticles transfected MSCs better than free plasmid DNA. ${ }^{74}$ Organicinorganic hybrid nanocrystals are the third type of gene nanocarriers, the hybrid nanocarrier enhanced gene transfection and transgene expression 20 and 3 times, as compared with the non-modified inorganic carbonate apatite nanocrystals and the commercially available Lipofectamine in the mouse embryonic cells, respectively, demonstrating the great potential of the hybrid nanocarriers for stem cell reprogramming. ${ }^{75}$

\section{Conclusions and Future Perspectives}

Nanoparticles as a carrier for preventing, monitoring, and treating DR have shown incomparable advantages, such as the early diagnosis, the non-invasiveness in treatment outcome monitoring, carrying therapeutic drugs to smoothly pass through the BRB, assisting therapeutic drugs in targeting to the retina and wrapping therapeutic drugs to avoid contact with other tissues in the eye. Although the development of nanomedicine and the clinical application of nanomaterials is still in the initial stage, the potential of nanotechnology is to be further utilized with the progress of research. However, before clinical trial application, each aspect of nanocarriers, whether it is of safety research, pharmacokinetics, or pharmacodynamics, shall be treated with caution to avoid additional damage to the eye. Further research on nanocarrier-based individualized therapies, for developing nanocarriers with different properties to carry therapeutic drugs is of great interest for the implementation and development of personalized medicine.

\section{Statement of Ethics}

This article does not contain any studies with human or animals performed by any of the authors.

\section{Acknowledgments}

We gratefully acknowledge Yujing He for providing intellectual support and technical assistance.

\section{Author contributions}

All authors made a significant contribution to the work reported, whether that is in the conception, study design, execution, analysis and interpretation, or in all these areas; took part in drafting, revising or critically reviewing the article; gave final approval of the version to be published; have agreed on the journal to which the article has been submitted; and agree to be accountable for all aspects of the work.

\section{Funding}

This research was supported by the National Natural Science Foundation of China (81700706), the 345 Talent Project of Shengjing hospital and the Clinical research project of Liaoning diabetes medical nutrition prevention society (LNSTNBYXYYFZXH-RS01B).

\section{Disclosure}

The authors declare no conflicts of interest for this work.

\section{References}

1. Lauri C, Glaudemans AWJM, Signore A. Leukocyte imaging of the diabetic foot. Curr Pharm Des. 2018;24(12):1270-1276. doi:10.2174/ 1381612824666180227094116

2. Lauri C, Tamminga M, Glaudemans AWJM, et al. Detection of osteomyelitis in the diabetic foot by imaging techniques: a systematic review and meta-analysis comparing MRI, white blood cell scintigraphy, and FDG-PET. Diabetes Care. 2017;40(8):1111-1120. doi: $10.2337 / \mathrm{dc} 17-0532$ 
3. Chan KH, Lim J, Jee JE, Aw JH, Lee SS. Peptide-peptide co-assembly: a design strategy for functional detection of C-peptide, a biomarker of diabetic neuropathy. Int J Mol Sci. 2020;21(24):9671. doi:10.3390/ijms21249671

4. Kim SS, Song SH, Kim IJ, et al. Urinary cystatin C and tubular proteinuria predict progression of diabetic nephropathy. Diabetes Care. 2013;36(3):656-661. doi:10.2337/dc12-0849

5. Satirapoj B, Aramsaowapak K, Tangwonglert T, Supasyndh O. Novel tubular biomarkers predict renal progression in type 2 diabetes mellitus: a prospective cohort study. J Diabetes Res. 2016;2016:9. doi:10.1155/2016/3102962.3102962

6. Mishra J, Mori K, Ma Q, et al. Amelioration of ischemic acute renal injury by neutrophil gelatinase-associated lipocalin. $J$ Am Soc Nephrol. 2004;15(12):3073-3082. doi:10.1097/01.ASN.000014501 3.44578 .45

7. Viau A, El Karoui K, Laouari D, et al. Lipocalin 2 is essential for chronic kidney disease progression in mice and humans. $J$ Clin Invest. 2010;120(11):4065-4076. doi:10.1172/jci42004

8. Yang YH, He XJ, Chen SR, Wang L, Li EM, Xu LY. Changes of serum and urine neutrophil gelatinase-associated lipocalin in type-2 diabetic patients with nephropathy: one year observational follow-up study. Endocrine. 2009;36(1):45-51. doi:10.1007/s12020-009-9187-x

9. Satirapoj B, Wang Y, Chamberlin MP, et al. Periostin: novel tissue and urinary biomarker of progressive renal injury induces a coordinated mesenchymal phenotype in tubular cells. Nephrol Dial Transplant. 2012;27(7):2702-2711. doi:10.1093/ndt/gfr670

10. Wantanasiri P, Satirapoj B, Charoenpitakchai M, Aramwit P. Periostin: a novel tissue biomarker correlates with chronicity index and renal function in lupus nephritis patients. Lupus. 2015;24 (8):835-845. doi:10.1177/0961203314566634

11. Satirapoj B. Tubulointerstitial biomarkers for diabetic nephropathy. J Diabetes Res. 2018;2018:2852398. doi:10.1155/2018/2852398

12. Wilkinson CP, Ferris FL, Klein RE; Global Diabetic Retinopathy Project Group. Proposed international clinical diabetic retinopathy and diabetic macular edema disease severity scales. Ophthalmology. 2003;110(9):1677-1682. doi:10.1016/S0161-6420(03)00475-5

13. Budzinskaya MV, Petrachkov DV, Savochkina OA, Arzhukhanov DD. K voprosu o klassifikatsii diabeticheskoĭ retinopatii [On classification of diabetic retinopathy]. Vestn Oftalmol. 2019;135:272-277. Russian. doi:10.17116/oftalma2019135052272.

14. Jiang Y. Effect of total retinal laser photocoagulation on diabetic retinopathy. Medical Equip. 2020;21:1002-2376.

15. Bi SS, Ping JH, Dai X. Progress in the treatment of diabetic retinopathy with retinal laser photocoagulation. $J$ Heze Med Coll. 2020;123:72-75.

16. Kleinmann G, Hauser D, Schechtman E, Landa G, Bukelman A, Pollack A. Vitreous hemorrhage in diabetic eyes previously treated with panretinal photocoagulation. Int Ophthalmol. 2008;28(1):29-34. doi:10.1007/s10792-007-9106-1

17. Early Treatment Diabetic Retinopathy Study research group. Photocoagulation for diabetic macular edema. Early treatment diabetic retinopathy study report number 1 . Arch Ophthalmol. 1985;103 (12):1796-1806. doi:10.1001/archopht.1985.01050120030015.

18. Striph GG, Hart WM Jr, Olk RJ. Modified grid laser photocoagulation for diabetic macular edema. The effect on the central visual field. Ophthalmology. 1988;95(12):1673-1679. doi:10.1016/S01616420(88)32957-X

19. Sims LM, Stoessel K, Thompson JT, Hirsch J. Assessment of visual-field changes before and after focal photocoagulation for clinically significant diabetic macular edema. Ophthalmologica. 1990;200 (3):133-141. doi:10.1159/000310094

20. Rohrschneider K, Bultmann S, Gluck R, Kruse FE, Fendrich T, Volcker HE. Scanning laser ophthalmoscope fundus perimetry before and after laser photocoagulation for clinically significant diabetic macular edema. Am J Ophthalmol. 2000;129(1):27-32. doi:10.1016/ S0002-9394(99)00270-6
21. Lee HJ, Kang TS, Kwak BS, Jo YJ, Kim JY. Long-term effect of panretinal photocoagulation on spectral domain optical coherence tomography measurements in diabetic retinopathy. Curr Eye Res. 2017;42(8):1169-1173. doi:10.1080/02713683.2017.1280510

22. Seiberth V, Alexandridis E, Feng W. Function of the diabetic retina after panretinal argon laser coagulation. Graefes Arch Clin Exp Ophthalmol. 1987;225:385-390. doi:10.1007/BF02334163

23. Russell PW, Sekuler R, Fetkenhour C. Visual function after pan-retinal photocoagulation: a survey. Diabetes Care. 1985;8:57-63. doi:10.2337/diacare.8.1.57

24. Deschler EK, Sun JK, Silva PS. Side-effects and complications of laser treatment in diabetic retinal disease. Ophthalmol. 2014;29(56):290-300. doi:10.3109/08820538.2014.959198

25. Zhang ZH, Xu H, Mo XH. Comparison of two vitrectomy for proliferative diabetic retinopathy. Int $J$ Ophthalmol. 2017;17 (6):1174-1177.

26. Brănişteanu DC, Bilha A, Moraru A. Vitrectomy surgery of diabetic retinopathy complications. Rom J Ophthalmol. 2016;60(1):31-36.

27. Tuuminen R, Sahanne S, Haukka J, Loukovaara S. Improved outcome after primary vitrectomy in diabetic patients treated with statins. Eur J Ophthalmol. 2016;26(2):174-181. doi:10.5301/ejo.5000657

28. Yamada Y, Suzuma K, Ryu M, Tsuiki E, Fujikawa A, Kitaoka T. Systemic factors influence the prognosis of diabetic macular edema after pars plana vitrectomy with internal limiting membrane peeling. Curr Eye Res. 2013;38(12):1261-1265. doi:10.3109/02713683.201 3.820327

29. Veritti D, Sarao V, Lanzetta P. A propensity-score matching comparison between 27-gauge and 25-gauge vitrectomy systems for the repair of primary rhegmatogenous retinal detachment. J Ophthalmol. 2019;2019:3120960. doi:10.1155/2019/3120960

30. Naruse Z, Shimada H, Mori R. Surgical outcomes of 27-gauge and 25-gauge vitrectomy day surgery for proliferative diabetic retinopathy. Int Ophthalmol. 2019;39(9):1973-1980. doi:10.1007/ s10792-018-1030-z

31. Nathan DM, Genuth S, Lachin J, et al. The effect of intensive treatment of diabetes on the development and progression of long-term complications in insulin-dependent diabetes mellitus. $N$ Engl J Med. 1993;329 (14):977-986. doi:10.1056/NEJM199309303291401

32. Lin WX, Zang J, Bao JL, Zhou LB, Zhu YD, Li Q. Compound Xueshuantong Capsule and Pancreatic Kikopeptidase in treatment of NPDR. Int J Ophthalmol. 2011;11:66-68.

33. Feng XF, Mai ZL, Huang BM, Han Q, Huang Q, Mai YX. Clinical analysis of insulin combined with calcium dobesilate in the treatment of early diabetic retinopathy. Mod Hosp. 2020;217:136-139.

34. Wang W, Lo ACY. Diabetic retinopathy: pathophysiology and treatments. Int $J$ Mol Sci. 2018;19(6):1816. doi:10.3390/ ijms 19061816

35. Wroblewski JJ, $\mathrm{Hu}$ AY. Topical Squalamine $0.2 \%$ and Intravitreal Ranibizumab $0.5 \mathrm{mg}$ as combination therapy for macular edema due to branch and central retinal vein occlusion: an Open-Label, randomized study. Ophthalmic Surg Lasers Imaging Retina. 2016;47 (10):914-923. doi:10.3928/23258160-20161004-04

36. Campochiaro PA, Khanani A, Singer M, et al. Enhanced benefit in diabetic macular edema from AKB-9778 Tie2 activation combined with vascular endothelial growth factor suppression. Ophthalmology. 2016;123(8):1722-1730. doi:10.1016/j.ophtha.2016.04.025

37. Jonas JB. Intravitreal triamcinolone acetonide for diabetic retinopathy. Ophthalmol. 2007;39:96-110. doi:10.1159/000098502

38. Phillips K, Katz HR. A comparison of the efficacy of dexamethasone and loteprednol on endotoxin-induced uveitis in rodents following topical ocular administration. Invest Ophthalmol Vis Sci. 2005;46:983.

39. Qian Y, Wenting C, Huizi J, Donghui Y, Tianyi SH, Jing Y. Application and safety of polyethyleneimine-modified sodium fluorescein nanoparticles in fundus fluorescein angiography. New Dev Ophthalmol. 2020;293:10-15. 
40. Vadanasundari V, Huang L, Zhang M, et al. Vanadium core-shell nanorods inspect metabolic changes of diabetic retinopathy. $A d v$ Funct Mater. 2020.

41. Gao X, Li Y, Wang H, Li C, Ding J. Inhibition of HIF-1 $\alpha$ decreases expression of pro-inflammatory IL- 6 and TNF- $\alpha$ in diabetic retinopathy. Acta Ophthalmol. 2017;95(8):746-750. doi:10.1111/ aos. 13096

42. Gong Q, Xie J, Li Y, Liu Y, Su G. Enhanced ROBO4 is mediated by up-regulation of HIF- $1 \alpha / \mathrm{SP} 1$ or reduction in miR-125b-5p/miR-146a5p in diabetic retinopathy. J Cell Mol Med. 2019;23(7):4723-4737. doi:10.1111/jcmm.14369

43. Iwase T, Fu J, Yoshida T, et al. Sustained delivery of a HIF-1 antagonist for ocular neovascularization. $J$ Control Release. 2013;172(3):625-633. doi:10.1016/j.jconrel.2013.10.008

44. Badr GA, Tang J, Ismail-Beigi F, Kern TS. Diabetes downregulates GLUT1 expression in the retina and its microvessels but not in the cerebral cortex or its microvessels. Diabetes. 2000;49(6):1016-1021. doi:10.2337/diabetes.49.6.1016

45. Ulas M, Orhan C, Tuzcu M, et al. Anti-diabetic potential of chromium histidinate in diabetic retinopathy rats. BMC Complement Altern Med. 2015;15:16. doi:10.1186/s12906-015-0537-3

46. Gao X, Han B. Preparation and pharmacodynamics of nanoparticles for diabetic retinopathy. Jilin University; 2020.

47. Hao H, Cai J, Jiang L. Effect of nanoparticle-mediated triamcinolone acetonide delivery on the treatment of diabetic rat retinopathy. Pract Drugs Clin. 2019;4:359-363.

48. Lu Y, Zhou N, Huang X, et al. Effect of intravitreal injection of bevacizumab-chitosan nanoparticles on retina of diabetic rats. Int $J \quad$ Ophthalmol. 2014;7(1):1-7. doi:10.3980/j.issn.22223959.2014.01.01

49. Araújo J, Garcia ML, Mallandrich M, Souto EB, Calpena AC. Release profile and transscleral permeation of triamcinolone acetonide loaded nanostructured lipid carriers (TA-NLC): in vitro and ex vivo studies. Nanomedicine. 2012;8(6):1034-1041. doi:10.1016/j. nano.2011.10.015

50. Araújo J, Nikolic S, Egea MA, Souto EB, Garcia ML. Nanostructured lipid carriers for triamcinolone acetonide delivery to the posterior segment of the eye. Colloids Surf B Biointerfaces. 2011;88(1):150-157. doi:10.1016/j.colsurfb.2011.06.025

51. Gonzalez-Mira E, Egea MA, Souto EB, Calpena AC, García ML. Optimizing flurbiprofen-loaded NLC by central composite factorial design for ocular delivery. Nanotechnology. 2011;22(4):045101. doi:10.1088/0957-4484/22/4/045101

52. Gonzalez-Mira E, Egea MA, Garcia ML, Souto EB. Design and ocular tolerance of flurbiprofen loaded ultrasound-engineered NLC. Colloids Surf B Biointerfaces. 2010;81(2):412-421. doi:10.1016/j. colsurfb.2010.07.029

53. Souto EB, Doktorovova S, Gonzalez-Mira E, Egea MA, Garcia ML. Feasibility of lipid nanoparticles for ocular delivery of anti-inflammatory drugs. Curr Eye Res. 2010;35(7):537-552. doi:10.3109/02713681003760168

54. Araújo J, Gonzalez-Mira E, Egea MA, Garcia ML, Souto EB. Optimization and physicochemical characterization of a triamcinolone acetonide-loaded NLC for ocular antiangiogenic applications. Int J Pharm. 2010;393(1-2):167-175. doi:10.1016/j. ijpharm.2010.03.034

55. Zhu HM, Huang PC, Zhao TT, et al. In vitro genotoxicity of silver nanoparticles and titanium dioxide nanoparticles. Hereditary. 2020;42:56-64.

56. Piao MY, Zhao JW. Research progress of magnetic iron oxide nanoparticles in biomedical application. Huaihai Med. 2020;38:110-113.

57. Xu LS, Li WD, Shi Q. Synthesis of mulberry leaf extract mediated gold nanoparticles and their ameliorative effect on Aluminium intoxicated and diabetic retinopathy in rats during perinatal life. J Photochem Photobiol B. 2019;196:111502. doi:10.1016/j.jphotobiol.2019.04.011
58. Amadio M, Pascale A, Cupri S, et al. Nanosystems based on siRNA silencing HuR expression counteract diabetic retinopathy in rat. Pharmacol Res. 2016;111:713-720. doi:10.1016/j.phrs.2016.07.042

59. Zamani M, Shirinzadeh A, Aghajanzadeh M, Andalib S, Danafar H. In vivo study of $\mathrm{mPEG}-\mathrm{PCL}$ as a nanocarriers for anti-inflammatory drug delivery of simvastatin. Pharm Dev Technol. 2019;24 (6):663-670. doi:10.1080/10837450.2018.1556689

60. Amato R, Giannaccini M, Dal Monte M, et al. Association of the somatostatin analog octreotide with magnetic nanoparticles for intraocular delivery: a possible approach for the treatment of diabetic retinopathy. Front Bioeng Biotechnol. 2020;8:144. doi:10.3389/ fbioe. 2020.00144

61. Shoval A, Markus A, Zhou Z, et al. Anti-VEGF-aptamer modified C-DotsA hybrid nanocomposite for topical treatment of ocular vascular disorders. Small. 2019;15(40):e1902776. doi:10.1002/smll.201902776

62. Kador PF, Wyman M, Oates PJ. Aldose reductase, ocular diabetic complications and the development of topical Kinostat. Prog Retin Eye Res. 2016;54:1-29. doi:10.1016/j.preteyeres.2016.04.006

63. Liu Z, Yu N, Holz FG, Yang F, Stanzel BV. Enhancement of retinal pigment epithelial culture characteristics and subretinal space tolerance of scaffolds with $200 \mathrm{~nm}$ fiber topography. Biomaterials. 2014;35(9):2837-2850. doi:10.1016/j.biomaterials.2013.12.069

64. Chang YC, Chen MH, Liao SY, et al. Multichanneled nerve guidance conduit with spatial gradients of neurotrophic factors and oriented nanotopography for repairing the peripheral nervous system. ACS Appl Mater Interfaces. 2017;9(43):37623-37636. doi:10.1021/ acsami.7b12567

65. Yan L, Zhao B, Liu X, et al. Aligned nanofibers from polypyrrole/ graphene as electrodes for regeneration of optic nerve via electrical stimulation. ACS Appl Mater Interfaces. 2016;8(11):6834-6840. doi:10.1021/acsami.5b12843

66. Jing Y, Moore LR, Williams PS, et al. Blood progenitor cell separation from clinical leukapheresis product by magnetic nanoparticle binding and magnetophoresis. Biotechnol Bioeng. 2007;96 (6):1139-1154. doi:10.1002/bit.21202

67. Nadri S, Kazemi B, Eeslaminejad MB, et al. High yield of cells committed to the photoreceptor-like cells from conjunctiva mesenchymal stem cells on nanofibrous scaffolds. Mol Biol Rep. 2013;40:3883-3890. doi:10.1007/s11033-012-2360-y

68. Ebrahimi-Barough S, Hoveizi E, Javidan $\mathrm{N}$, et al. Investigating the neuroglial differentiation effect of neuroblastoma conditioned medium in human endometrial stem cells cultured on 3D nanofibrous scaffold. J Biomed Mater Res A. 2015;103:2621-2627. doi:10.1002/ jbm.a.35397

69. Froelich K, Pueschel RC, Birner M, et al. Optimization of fibrinogen isolation for manufacturing autologous fibrin glue for use as scaffold in tissue engineering. Artif Cells Blood Subst Biotech. 2010;38:143-149. doi:10.3109/10731191003680748

70. Soleimannejad M, Ebrahimi-Barough S, Soleimani M, et al. Fibrin gel as a scaffold for photoreceptor cells differentiation from conjunctiva mesenchymal stem cells in retina tissue engineering. Artif Cells Nanomed Biotechnol. 2018;46(4):805-814. doi:10.1080/ 21691401.2017.1345922

71. Li S, Huang L. In vivo gene transfer via intravenous administration of cationic lipid-protamine-DNA (LPD) complexes. Gene Ther. 1997;4(9):891-900. doi:10.1038/sj.gt.3300482

72. Li S, Rizzo MA, Bhattacharya S, Huang L. Characterization of cationic lipid-protamine-DNA (LPD) complexes for intravenous gene delivery. Gene Ther. 1998;5(7):930-937. doi:10.1038/sj.gt.3300683

73. Long J, Kim H, Kim D, Lee JB, Kim DH. A biomaterial approach to cell reprogramming and differentiation. J Mater Chem B. 2017;5 (13):2375-2379. doi:10.1039/C6TB03130G

74. Cao B, Qiu P, Mao C. Mesoporous iron oxide nanoparticles prepared by polyacrylic acid etching and their application in gene delivery to mesenchymal stem cells. Microsc Res Tech. 2013;76(9):936-941. doi:10.1002/jemt.22251 
75. Kutsuzawa K, Chowdhury EH, Nagaoka M, Maruyama K, Akiyama Y, Akaike T. Surface functionalization of inorganic nano-crystals with fibronectin and E-cadherin chimera synergistically accelerates trans-gene delivery into embryonic stem cells. Biochem Biophys Res Commun. 2006;350(3):514-520. doi:10.1016/j.bbrc.2006.09.081

76. Fangueiro JF, Andreani T, Egea MA, et al. Design of cationic lipid nanoparticles for ocular delivery: development, characterization and cytotoxicity. Int J Pharm. 2014;461(1-2):64-73. doi:10.1016/j. ijpharm.2013.11.025

77. Kompella UB, Amrite AC, Pacha Ravi R, Durazo SA. Nanomedicines for back of the eye drug delivery, gene delivery, and imaging. Prog Retin Eye Res. 2013;36:172-198. doi:10.1016/j. preteyeres.2013.04.001

78. Yang J, Cai L, Zhang S, Zhu X, Zhou P, Lu Y. Silica-based cerium (III) chloride nanoparticles prevent the fructose-induced glycation of $\alpha$ crystallin and $\mathrm{H}_{2} \mathrm{O}_{2}$-induced oxidative stress in human lens epithelial cells. Arch Pharm Res. 2014;37(3):404 411. doi:10.1007/s12272-0130195-2

79. Jo DH, Kim JH, Yu YS, Lee TG, Kim JH. Antiangiogenic effect of silicate nanoparticle on retinal neovascularization induced by vascular endothelial growth factor. Nanomedicine. 2012;8(5):784-791. doi:10.1016/j.nano.2011.09.003

80. Gurunathan S, Lee KJ, Kalishwaralal K, Sheikpranbabu S, Vaidyanathan R, Eom SH. Antiangiogenic properties of silver nanoparticles. Biomaterials. 2009;30(31):6341-6350. doi:10.1016/j. biomaterials.2009.08.008
81. Kim JH, Kim MH, Jo DH, Yu YS, Lee TG, Kim JH. The inhibition of retinal neovascularization by gold nanoparticles via suppression of VEGFR-2 activation. Biomaterials. 2011;32(7):1865-1871. doi:10.1016/j.biomaterials.2010.11.030

82. Varshochian R, Jeddi-Tehrani M, Mahmoudi AR, et al. The protective effect of albumin on bevacizumab activity and stability in PLGA nanoparticles intended for retinal and choroidal neovascularization treatments. Eur J Pharm Sci. 2013;50(3-4):341-352. doi:10.1016/j. ejps.2013.07.014

83. Bysell H, Månsson R, Hansson P, Malmsten M. Microgels and microcapsules in peptide and protein drug delivery. Adv Drug Deliv Rev. 2011;63(13):1172-1185. doi:10.1016/j.addr.2011.08.005

84. Danhier F, Ansorena E, Silva JM, Coco R, Le Breton A, Préat V. PLGA-based nanoparticles: an overview of biomedical applications. J Control Release. 2012;161(2):505-522. doi:10.1016/j. jconrel.2012.01.043

85. Pusparajah P, Lee LH, Abdul Kadir K. Molecular Markers of Diabetic Retinopathy: Potential Screening Tool of the Future? Front Physiol. 2016;7:200. doi:10.3389/fphys.2016.00200
International Journal of Nanomedicine

\section{Publish your work in this journal}

The International Journal of Nanomedicine is an international, peerreviewed journal focusing on the application of nanotechnology in diagnostics, therapeutics, and drug delivery systems throughout the biomedical field. This journal is indexed on PubMed Central, MedLine, CAS, SciSearch ${ }^{\circledR}$, Current Contents ${ }^{\circledR} /$ Clinical Medicine,
Dovepress

Journal Citation Reports/Science Edition, EMBase, Scopus and the Elsevier Bibliographic databases. The manuscript management system is completely online and includes a very quick and fair peer-review system, which is all easy to use. Visit http://www.dovepress.com/ testimonials.php to read real quotes from published authors. 